\title{
Assessing the Effectiveness of Indoor Residual Spraying (IRS) in the Prevention of Malaria among Children of Under Five Years Old In Ikorodu Local Government, Lagos State, Nigeria
}

\author{
Oluwadamisi Tayo-Ladega \\ CEO His Marvellous Grace Support Foundation, Nigeria; PHD STudent, Bangor University, UK \\ *Corresponding Author: Oluwadamisi Tayo-Ladega, CEO His Marvellous Grace Support \\ Foundation, Nigeria; PHD STudent, Bangor University, UK
}

\begin{abstract}
This study assessed the effectiveness of IRS in the prevention of malaria among under five years age children in Ikorodu area of Lagos State, Nigeria. The questionnaire consists of closed-ended questions which address the current status of IRS in Ikorodu Local Government Area. The questionnaires were administered to 400 respondents but only 215 questionnaires were carefully and fully completed for data analysis. Chi-square was employed for data analysis. From the information, there is a high level of literacy among the respondents in Ikorodu Local Government Area of Lagos state. This is a pointer to the fact that the respondents will be knowledgeable about IRS and its application. IRS is very effective more than other types of malaria preventives, and the chemical in IRS cannot kill under five years old children as perceived by respondents in the study area. This study found that there is an association between the education level of the respondent and their knowledge of IRS in Ikorodu Local Government, Lagos State, Nigeria. As a result of this, it can be observed that the usage of IRS is effective on under five years age children, and the citizens are educated about the usage of IRS. Despite the fact that the respondents are knowledgeable about IRS usage and that IRS is effective, there is a need for continous education programmes, engineering solutions, and some form of enforcements so that the effectiveness will be a sweeping transformation.
\end{abstract}

Keywords: Malaria; IRS; Prevention; Under five years; Nigeria

\section{INTRODUCTION}

Indoor residual spraying (IRS) is one of the primary vector control interventions for reducing and interrupting malaria transmission. In recent years, however, it has received relatively little attention. Recent data reconfirms the efficacy and effectiveness of IRS in malaria control in countries where it was implemented well (WHO, 2006).

Effective implementation of IRS with DDT or other recommended insecticides should be a central part of national malaria control strategies where this intervention is appropriate. It is implemented to reduce malaria morbidity and mortality and accelerate progress towards global and national malaria targets. However, there are important considerations that must be taken into account when considering whether to introduce or scale up the IRS. In particular, there must be sufficient capacity to deliver the intervention effectively, prevent unauthorized and unrecommended use of public health pesticides, and manage insecticide resistance. Intensified research efforts are needed, for example, to develop new insecticides, long-acting formulations and improved application technologies (WHO, 2006).

Indoor residual house spraying (IRS) mainly with dichlorodiphenyltrichloroethane (DDT) was the principal method by which malaria was eradicated or greatly reduced in many countries in the world between the 1940s and 1960s. In sub-Saharan Africa, early malarial eradication pilot projects also showed that malaria is highly responsive to vector control by IRS but transmission could not be interrupted in the endemic tropical and lowland areas. Large-scale malarial control operations based on IRS with DDT and benzene hexachloride (BHC) were initiated in many countries to varying degrees including Nigeria.

There were an estimated 247 million malaria cases among 3.3 billion people at risk in 2006, causing nearly one million deaths, mostly of children under five years. One hundred and nine countries were endemic for malaria in 2008, 45 within the WHO African region (WHO 2008). Ninety per cent of all malaria cases occur in 
sub-Saharan Africa, in areas of stable endemic transmission, and around $20 \%$ of all deaths in children have been attributed directly to malaria (Snow 1999). The disease causes widespread premature death and suffering, imposes financial hardship on poor households, and holds back economic growth and improvements in living standards. The rapid spread of resistance first to chloroquine and now to sulfadoxine- pyrimethamine has greatly increased the cost and difficulty of malaria case management, particularly in Africa (RBM 2005). Estimates have suggested that malaria costs the African countries US $\$ 12$ billion annually and may considerably retard economic development (Sachs 2002).

Primary prevention of malaria is essentially achieved through two main vector control interventions:

1. Indoor (house) residual insecticide spraying (IRS); and

2. Insecticide-treated (mosquito) nets (ITNs).

The health effects of ITNs have been comprehensively summarized in two (Lengeler 2004) and one for pregnant women (Gamble 2006). IRS has a long and distinguished history in malaria control. Using mainly dichlorodiphenyl-trichloroethane (DDT), malaria was eliminated or greatly reduced as a public health problem in Asia, Russia, Europe, and Latin America (Schiff 2002; Lengeler 2003; Roberts 2004). IRS continues to be used in many parts of the world, with the services provided by the public health system or by a commercial company (usually for the benefit of its employees). There is no IRS programme known to us in which beneficiaries were expected to contribute financially.

Control of malaria represents one of the world's greatest public health challenges, especially in sub-Saharan Africa where most of the disease occurs nowadays. In the past decades, efforts to control malaria have been met with mixed success. Since the discovery of the connection between Anopheles vectors and malaria transmission in 1897 , vector control strategies have been the most widely used malarial control measures. Before World War II vector control measures included environmental sanitation through drainage and landfills to eliminate the larval mosquito habitat; biological control through the use of larvivorous fish in ponds; larviciding with oil and Paris green. All these methods were effective, especially in Europe, but malaria continued to be a problem on a global scale (Najera 2000).

Malaria is a huge burden on the Nigerian health system; it is also a cause and consequence of poverty, which has important implications for the economic development of the country. Recognizing the morbidity and mortality from malaria in African countries such as Nigeria led to the formation of the rollback malaria (RBM) global partnership in 1998 (WHO RBM, 2002). In 2008, the country Nigeria accounted for a quarter of all malaria cases on the African continent (WHO, 2008).

In 2010, there were estimated to be about 219 million malaria cases in the world (with estimates ranging from 154 million to 289 million) and 660, 000 deaths (with estimates ranging from 610,000 to 971,000 ). The countries contributing the most malaria cases were the Democratic Republic of the Congo (DRC), Nigeria, and India, with the DRC and Nigeria accounting for $>40 \%$ of deaths (World Health Organization (WHO), 2012). Until substantial progress is made in these countries, the millennium development goal (MDG) of halting and reversing the incidence of malaria by 2015 will not be achieved (Lauretta, 2014).

With a population of 162 million people (WHO, 2012), Nigeria has the largest population in Africa at risk of acquiring malaria. The current goal of RBM is to reduce malaria incidence by $75 \%$ by the end of 2015 compared to levels in the year 2000 (WHO, 2012). The last decade has witnessed a large increase in the number of resources dedicated to fighting malaria (Sarbib et al., 2006; Snow and Marsh, 2010; Snow et al., 2010). Institutions such as the Global Fund to fight AIDS, Tuberculosis and Malaria (GFATM), the World Bank, and the US President's Malaria Initiative (PMI) have more than doubled funding for malaria control, especially in Sub-Saharan Africa (SSA) (Grabowsky, 2008; Pigott et al., 2012, Lauretta, 2014). Increase in funding has allowed for measures to prevent and control malaria such as universal free bed net distributions in many SSA countries, the use of Indoor Residual Spray (IRS).

According to the World Health Organization (2013), malaria is a completely preventable disease. In the same vein, about 3.4 billion people are at malaria risk globally and about 1.2 billion people at high risk. In 2012, malaria was responsible for the death of approximately 
482,000 under-five children even though there are several measures put into place to combat malaria in various endemic countries the same year (World Health Organization (2013). As a result of several endemic effects of malaria, it remains a major public health concern particularly in sub-Saharan Africa and other parts of the developing world. Malaria remains one of the major public health diseases in subSaharan Africa, contributing significantly to high morbidity and mortality rate in the region (Narasimhan and Attaran, 2003; UNESCO, 2008; Federal Ministry of Health, 2011). In Nigeria, more than $90 \%$ of the total population was estimated to be at risk of the endemic while not less than $50 \%$ of the population suffers from malaria each year (FMOH, 2011). Children under 5 years of age and pregnant women have also been identified as the most vulnerable demographic group to the infection (Orimadegun, Fewole, Okereke, Akinbami and Sodeinde, 2002). Malaria is responsible for around $60 \%$ of the out-patient visits to health facilities, $30 \%$ of childhood death, $25 \%$ of death in children under one year and $11 \%$ of maternal deaths (National Population Commission, 2008; Noland et al., 2014). Similarly, about $70 \%$ of pregnant women suffer from malaria, which contributes to maternal anaemia, low birth weight, stillbirths, abortions and other pregnancy-related complications (Federal Ministry of Health Abuja, 2005). The financial loss due to malaria is estimated to be about 132 billion Naira (\$797 million) annually in form of treatment costs, prevention costs and loss of man-hours (Noland et al., 2014; World Health Organization, 2012).

Over the years, the common approach to combat and prevent malaria in Nigeria is the application of indoor residual spray (IRS). There is a need to assess the effectiveness of IRS if indeed it meets the present need, most especially to prevent malaria among children of under five years old. IRS is one of three main interventions recommended by the World Health Organization (WHO) for the control of malaria. It is also one of the strategies to prevent malaria. IRS is the application of long-lasting chemical insecticides on the walls and roofs of all houses and domestic animal shelters, to kill the adult mosquito vector that comes in contact with those surfaces. The intervention involves repeated spraying over several years.

According to WHO (2006), WHO's Global Malaria Programme recommends the following three primary interventions that must be scaled up in countries to effectively respond to malaria, towards achieving the Millennium Development Goals for malaria by 2015 and other health targets:

1. Diagnosis of malaria cases and treatment with effective medicines;

2. Distribution of insecticide-treated nets (ITNs) to achieve full coverage of populations at risk of malaria; and

3. Indoor residual spraying (IRS) as a major means of malaria vector control to reduce and eliminate malaria transmission including, where indicated, the use of DDT.

Scaling up access and achieving high coverage of these effective interventions, particularly to populations who are at the highest risk of malaria, and sustaining their implementation, remain major challenges for achieving current global malaria control goals.

IRS is the application of long-acting chemical insecticides on the walls and roofs of all houses and domestic animal shelters in a given area, to kill the adult vector mosquitoes that land and rest on these surfaces. The primary effects of the IRS on curtailing malaria transmission are:

1. To reduce the life span of vector mosquitoes so that they can no longer transmit malaria parasites from one person to another, and

2. To reduce the density of the vector mosquitoes (WHO, 2006).

In some situations, the IRS can lead to the elimination of locally important malaria vectors. Some insecticides also repel mosquitoes and by so doing reduce the number of mosquitoes entering the sprayed room, and thus humanvector contact (WHO, 2006).

Despite its initial widespread use and contribution to the success of malaria eradication and control efforts, in recent years, the use of IRS has declined. This is due in part to lack of government commitment and financing to sustain these efforts over the long term and to concerns about insecticide resistance and community acceptance. However, another important factor has been general disapproval of DDT use, due to fears of its harmful effects on the environment and on human health, fears which are unjustified when DDT is used appropriately for IRS. In the past, DDT was widely used in agriculture and 
domestic hygiene, leading to a massive release of the compound into the environment (WHO, 2006).

In the study conducted by Dr Sam Awolola who is the Public Health Entomologist HOD in the Nigerian Institute of Medical Research, Lagos, Nigeria, titled; baseline information for the implementation of indoor residual spraying: the Nigeria experience. He stated that even though Indoor Residual Spraying (IRS) is a highly effective method of malaria control, it remains underutilized in many parts of Africa including Nigeria. It should be noted that in the quest to reduce the malaria burden, Nigeria adopted Integrated Vector Management (IVM) in 2006, meanwhile, IRS is a key component of IVM and its effective implementation requires evidencebased information. Does it mean that the IRS is not effective?

This paper aim at assessing the effectiveness of indoor residual spray in the prevention of malaria among children of under five years old in Ikorodu local government, Lagos state. The objectives are to assess the effectiveness of IRS on under five years age children and to determine the extent to which the citizens are educated about the IRS.

Ikorodu is a city in Lagos State, Nigeria. Located North East of Lagos State along the Lagos Lagoon, it shares a boundary with Ogun State. As of the 2006 Census, Ikorodu had an enumerated population of 535,619. There are three principals in Ikorodu: ISHEI; IJOMU; and AGA. The Ituns: (minor areas). The Itas (squares)

Ikorodu in the last 40 years or so, did not extend beyond the inner circular route: Ojubode, Etunrenren, Epadi, (Ayangbunren Road) Oju Ogbe, Ireshe, Eluku Street, Ojubode Street Ojubode Orere Garage (Oriwu Hotel) Lagos Road, Ikorodu Township has now metamorphosed into a Metropolis over a million people. Therefore, extended to Aga Titun, Agbele, Erunwen, Solomade, Eyita, Agbala, Lowa, Gbasemo, Oke Ota Ona etc.

It has again extended to greater Ikorodu by the creation of Ikorodu West Development Council Area, Owutu as the headquarters which includes Ipakodo, Majidun, Otowolo, Oriokuta, Ajaguro, Ogolonto, Araromi-Solebo etc. and Ikorodu North Local Council Development Area, that includes Isiwu, Odogunyan, Odonla, Odokekere, Okegbegun, Rofo, Lasunwon, Agbede, Losi Oba, Erikorodo, Araromi, Mojoda, Oke Ogbodo, Laiyeode/Akaun, Liadi, Maya, Parafa, Adamo, Aleke etc.

Surrounding major towns that makeup Ikorodu Divisions are Imota, Ijede and Igbogbo and all these major towns constitute their own Local Council Development Area with their respective traditional rulers (Obas). Main occupations of Ikorodu people are trading (commerce) and farming. Industry:

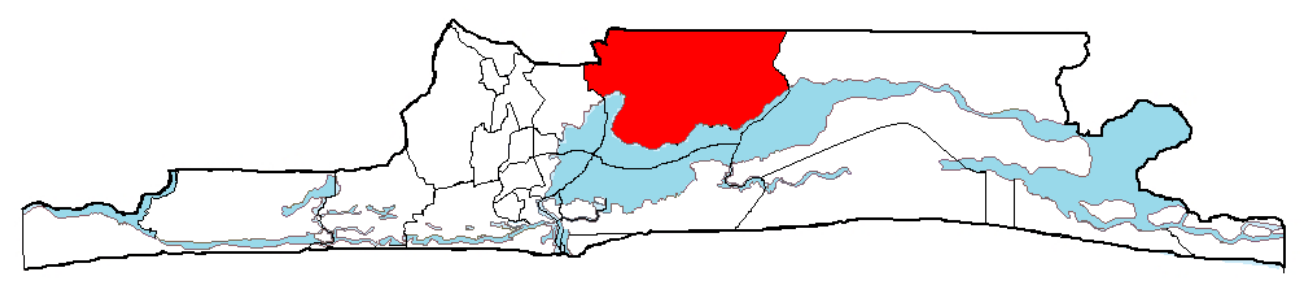

Figure1.1. Ikorodu Map

Source: (Adeniran and Oyemade, 2016)

In Ikorodu, the type of dominating building structure is modern houses whereby more than $80 \%$ of

houses are constructed with concrete blocks and corrugated iron sheets and ceilings. This implies that the housing type and structures are adequate for the IRS. Also, it implies that more than $90 \%$ of practices are unlikely to affect spray surfaces. There is a high level of awareness and willingness to participate in a proposed pilot IRS test. The major malaria vector species in Ikorodu is An gambiae s.s, their resting and feeding behaviour is endophillic and endophagic in nature. The insecticide tested in Ikorodu are Deltamethrin, Lambda-cyhalothrin, DDT and Bifenthrin. They all exposed 100\% Anopheles malaria vector although DDT seems to be a resistance to human health when examined under 24 hours post-exposure mortality (Nigerian Institute of Medical Research, Lagos, Nigeria). 
Assessing the Effectiveness of Indoor Residual Spraying (IRS) in the Prevention of Malaria among Children of Under Five Years Old In Ikorodu Local Government, Lagos State, Nigeria

\section{LITERATURE REVIEW}

\section{Malaria}

Malaria is a debilitating febrile and lifethreatening illness caused by a parasite called Plasmodium. Its route of transmission remains as bites from infected female anopheles mosquitoes. Environmental factors and behavioural patterns of vectors and human populations combine to provide favourable conditions for malaria transmission (Boutin et $a l ., 2005)$. Proven effective options to reduce morbidity and mortality include early diagnosis, combined with prompt effective therapy and malaria prevention through reduction of humanvector contact, especially with the use of IRS.

Perceptions about malaria illness, particularly households' perceived susceptibility and beliefs about the seriousness of the disease, are important preceding factors for decision-making concerning preventive and curative actions (Rakhshani et al., 2003). The understanding of the possible causes, modes of transmission, and individual preference and decision-making about the adoption of preventive and control measures vary from community to community and among individual households (Adongo, Kirkwood and Kendall, 2005). There have been a considerable number of reports about knowledge, attitudes, and practices relating to malaria and its control from different parts of Africa.

The availability of dichlorodiphenyltri chloroethane (DDT) and other insecticides in the 1940s marked a new era for malaria control in the world. The effectiveness of DDT against indoor resting mosquitoes led to the adoption of the Global Eradication Programme of Malaria in 1955, coordinated and supported by the World Health Organization (WHO). For the first 10 years (1957-66) the results were spectacular; malaria was completely eradicated in the United States as well as in the former Soviet Union and European countries. Disease incidence was also significantly reduced in many countries in the tropical region of South-East Asia, India and South America. However, gains made in some of the countries, particularly in the tropical regions, could not be sustained and there were reverses due to financial, administrative or operational problems, resistance or behaviour of vectors, or to the inadequate development of basic health services (Najera 2001). The timelimited eradication policy was eventually abandoned in 1969 and replaced by a long-term
Global Malaria Control Strategy in 1992 (Mabaso et al., 2004).

Achieving sustainable control of the disease depend on extensive public health promotional programs which focus on current and proven methods of malaria prevention and management. While much is known about vector biology and behaviour and the malaria parasites, the importance of human behaviour in malaria transmission has not been critically evaluated. Studies focusing on the current practices of malaria prevention and treatment options in the population are sparse. Thus, it is expedient to evaluate current knowledge of malaria prevention practices and management options as well as the uptake of the management options.

Malaria is caused by one of four species of Plasmodium parasites that are transmitted by various species of mosquitoes in the genus Anopheles. Malaria is a parasitic disease primarily caused by plasmodia of various types:

1. Plasmodium ovale;

2. Plasmodium malaria;

3. Plasmodium vivat; and

4. Plasmodium falciparum (FMOH, 2011).

Among these four species of plasmodia, plasmodium falciparum is said to be the cause of the most severe malaria illness and death throughout the world (WHO cited in $\mathrm{FMOH}$, 2003). Plasmodium falciparum is also identified as being the most devastating to Nigeria (FMOH, 2004). According to the Federal Ministry of Health (2011), the transmission of the parasite is facilitated through the bite of female anopheles mosquitoes.

\section{Situation of Malaria in Nigeria}

Although malaria is a parasitic disease which is easily preventable and curable (BASICS, 2001), it remains one of the major public health problems in Nigeria (Osero, Oteino\&Oraqo, 2005). According to the Federal Ministry of Health (2001), the malaria situation in the country has been deteriorating despite the numerous interventions instituted so far. The failure of the interventions has been attributed to socio-cultural, economic and political factors (FMOH, 2001 in Lauretta, 2014).

The prevalence of malaria in Nigeria has also been attributed to both behavioural and nonbehavioural factors (Oyedeji et al, 2009). The 
behavioural factors entail some cultural practices, which promote mosquito breeding and mosquitoes access to the people as well as the failure of high-risk populations to use technologies appropriately (FMOH, 2004). The non-behavioural factors on other hand include geographical or ecological peculiarities, the availability of mosquitoes and the presence of plasmodia $(\mathrm{FMOH}, 2011)$. It is necessary to have a thorough understanding of both factors to design appropriate interventions for the effective mitigation of malaria in the country $(\mathrm{FMOH}$, 2004 in Lauretta, 2014).

According to FMOH (2001), malaria is a major cause of morbidity and mortality in Nigeria. PMI (2009) noted that it is endemic throughout the country with more than $90 \%$ of the population at risk of the disease and not less than $50 \%$ of the entire population gets affected each year (FMOH, 2001). However, children aged less than 5 years, pregnant women, visitors from non-malarious regions and those with sickle cell anaemia have been identified as the population with the highest risk of infection (Orimadegun, et al, 2007). FMOH (2001) also noted that the disease is the most common cause of outpatient attendance across all age groups.
WHO (2000) reported that the disease accounts for $20-30 \%$ of under-five mortality and that in highly malarious areas of the country the death toll could be as high as 50\%. The Federal Ministry of Health (2001) also noted that Malaria accounts for $25 \%$ of infant mortality and $30 \%$ of childhood mortality. The results of the malaria situation in Nigeria across the six geographical zones as reported by $\mathrm{FMOH}$ (2004) confirmed that malaria is a major cause of morbidity and mortality especially among vulnerable groups including women and children aged less than 5 years.

The spread of malaria across the six geopolitical zones of the country as reported by FMOH (2003) were as follow:

1. South-South $32.7 \%$;

2. South-West $36.6 \%$;

3. South-East $30.7 \%$;

4. North-Central 58.8\%;

5. North-East 55.3\%; and

6. North-West $33.6 \%$.

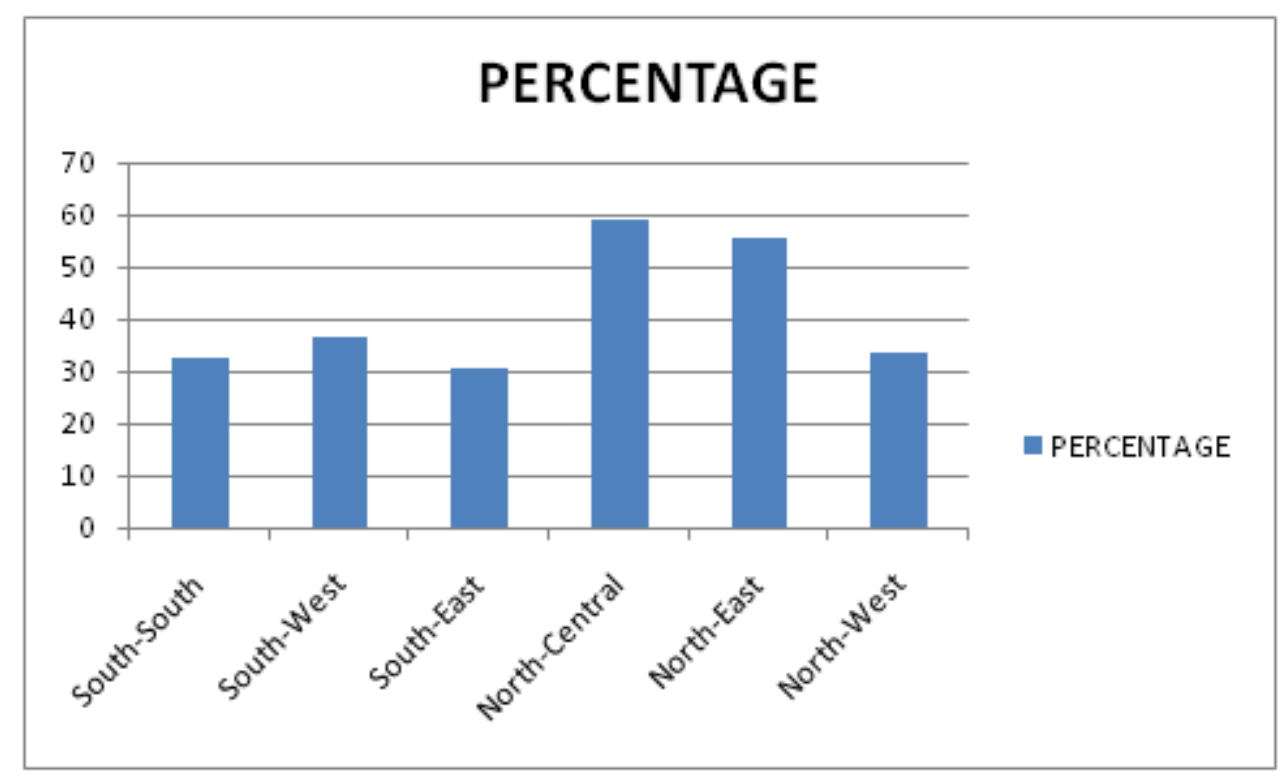

Figure2.1. Malaria across the six geo-political zones in Nigeria

Source: Authors' computation

Malaria was also found to co-exist with some other prevailing health problems. It was found that malaria accounted for $11 \%$ of maternal deaths in the study areas while $63 \%$ of the diseases were reported in healthcare facilities across the six geographical zones. (FMOH, 2001; FMOH 2003).
In addition to being a major cause for high morbidity and mortality rate in Nigeria, malaria also constitutes a major-economic burden on affected communities in Africa, including Nigeria (WHO, 2005). It was reported that in 1997, sub-Saharan spent more than US\$2billion on malaria (WHO). Malaria 
reduces human work capacity and productivity. Hence, it adversely affects the socio-economic development of the nation (FMOH, 2001; Breman, Alilio\& Mills, 2004). The high rate of absenteeism among school children in Nigeria is partly attributed to malaria (Oyedeji et al, 2009). In general, malaria causes great suffering and adversely affects the social and psychological wellbeing of individuals, families and the nation at large (FMOH, 2004).

\section{Control of Malaria}

One of the major ways to control malaria is through the use of insecticide (IRS) that prevent these mosquitoes from feeding on people, most especially the under five years old. IRS is one of three main interventions recommended by the World Health Organization (WHO) for the control of malaria. It is also one of the strategies to prevent malaria. IRS is the application of longlasting chemical insecticides on the walls and roofs of all houses and domestic animal shelters, to kill the adult mosquito vector that comes in contact with those surfaces. The intervention involves repeated spraying over many years.

Despite the cost of procuring IRS, they have been demonstrated by various studies to be both cost-effective and sustainable in the long run (WHO, 2006). As part of a larger preventive program, they aid in the reduction of malaria episodes in malaria-endemic regions. Consistent use of IRS can cause a reduction in malaria incidence, and also reduce malaria-related mortality in children under five years old.

In Africa, several malarial eradication pilot projects were initiated between the 1940s and the 1960s in countries such as Liberia, Cameroon, Nigeria, Senegal, Burkina Faso, Benin, Togo, Rwanda, Burundi, Uganda, Tanzania and Kenya. The intention was to assist governments to improve techniques to the point where transmission was interrupted and eradication could be undertaken. These pilot projects demonstrated that malaria was highly responsive to control by indoor residual spraying (IRS) with insecticides (mainly DDT). Significant reductions in anopheline vectors and malaria were recorded but transmission could not be interrupted (Payne et al. 1976; Kouznetsov 1977; Bradley 1991; Najera 2001; in Mabaso et al., 2004).
Subsequently, international interest in malaria and funding for malarial research and control declined in most countries on the continent. As a result, residual spraying was not taken to scale in large parts of sub-Saharan Africa except for southern Africa and islands such as Reunion, Mayotte, Zanzibar, Cape Verde and Sao Tome. In southern Africa, the first experimental adult mosquito control with pyrethrum was carried out in 1931 in KwaZulu-Natal, South Africa and this led the way for the worldwide use of residual insecticides against adult mosquitoes (de Meillon 1936). By the 1940s, large-scale malarial control operations based on housespraying with DDT and benzene hexachloride (BHC) were successfully initiated in South Africa, Zimbabwe and Swaziland. The danger of unexpected epidemics was minimized; morbidity and mortality were drastically reduced, and in certain areas such as southern KwaZulu-Natal the disease was eradicated (Kouznetsov 1977).

Today malaria is a resurging global phenomenon, with explosive epidemics, altered geographical distribution and resurgence in areas where it had been brought to low levels (Roberts et al. 2000). It is important therefore to look at the history of malaria and its control in regions where significant and sustained strides were made towards control, particularly in Africa, the historical impact of vector control on the malarial situation in Nigeria, and how the control programmes evolved in the country with an emphasis on the use of IRS, which has been and continues to be the backbone of malarial control in Nigeria.

To assess the effectiveness of IRS, IRS is thought to operate both through repelling mosquitoes from entering houses and by killing female mosquitoes that are resting inside houses after having taken a blood meal. This implies that the IRS is most effective against mosquito species that are resting indoors (so-called endophilic mosquitoes). Whereas ITNs show a high degree of personal protection, IRS relies largely on a vectorial mass effect: the increased mortality of adult vectors mostly the following feeding leads to a reduction in transmission. Spraying needs to be carried out between once and three times per year; the timing depending on the insecticide and the seasonality of transmission in a given setting. Reviewing the advantages 
and disadvantages of each insecticide is beyond the scope of this review and can be found among others in Najera, 2001 (Pluess et al., 2010).

IRS has the advantage of being able to make use of a much wider range of insecticide products in comparison to ITNs, for which pyrethroids are the only class of insecticide currently used. The World Health Organization (WHO) recommends several insecticides for individual residual spraying: DDT wettable powder (WP); malathion WP; fenitrothion WP; pirimiphos-methyl WP and emulsifiable concentrate (EC); bendiocarb WP; propoxur WP; alpha-cypermethrin WP \& suspension concentrate (SC); cyfluthrin WP; deltamethrin WP; etofenprox WP; lambdacyhalothrin capsule suspension (CS) and WP (WHOPES 2007). This extended range of insecticides has important benefits for the management of insecticide resistance and hence the long-term sustainability of vector control (pyrethroid resistance has already been reported in many parts of tropical Africa and other parts of the world among populations of the major malaria vectors). The potentially adverse effect of insecticides used for IRS, especially DDT, is an important issue (Pluess et al., 2010). Insecticide spraying is often done on a very large scale to maximize the mass effect of the insecticide; thus randomized controlled trial (RCT) designs may not always be feasible. However, controlled before-andafter studies (CBA) are feasible, as are interrupted time series (ITS) (Pluess et al., 2010).

\section{Indoor Residual Spraying (IRS)}

IRS is the application of long-acting chemical insecticides on the walls and roofs of all houses and domestic animal shelters in a given area, to kill the adult vector mosquitoes that land and rest on these surfaces. The primary effects of the IRS on curtailing malaria transmission are:

1. To reduce the life span of vector mosquitoes so that they can no longer transmit malaria parasites from one person to another, and

2. To reduce the density of the vector mosquitoes (WHO, 2006).

In some situations, the IRS can lead to the elimination of locally important malaria vectors. Some insecticides also repel mosquitoes and by so doing reduce the number of mosquitoes entering the sprayed room, and thus human-vector contact (WHO, 2006).

\section{Empirical Review}

It was found that under-five caregivers visit a variety of sources such as patent medicine vendors, traditional healers, health centres, hospitals, private clinics, drug hawkers and diviners to obtain medications (Adeniyi et al, 2002; Oyedeji et al, 2009; Lauretta, 2014). Generally, malaria preventive health behaviours in Nigeria are poor (WHO 2000; FMOH, 2004; Oyedeji et al. 2009; FMOH, 2011; Lauretta, 2014).

When comparing the extent of using IRS and bed net, studies have shown that the use of bed net is generally poor in Nigeria, among all categories of people (NetMark, 2001, Oyedeji et al, 2009; Lauretta, 2014). The survey revealed that the preventive measures reportedly adopted by some respondents included the use of the following: window/door nets $32.6 \%$. insecticides aerosol $-33.8 \%$, repellants $-22.7 \%$ and herbs $-23 \%$ (Fmolt, 2000). Net mark (2001) observed that only $12 \%$ of households in Nigeria reported owning mosquito nets.

In a study carried out by Oyedeji et al (2009), only $1 \%$ of children between 3 months and 13 years used insecticide-treated nets, $4.7 \%$ used alternative barrier methods while the remaining $94.3 \%$ used more of the specified methods including IRS. The four alternative barrier methods include insecticide sprays, mosquito repellent coils, topical repellent creams and untreated bed nets (Oyedeji et al, 2009). The reasons given by the $94.3 \%$ of children who did not use any of the methods as identified by Oyedeji et al (2009) include ignorance, unavailability, cost, considered unnecessary, cumbersome to use, refusal of the child to sleep under nets and allergy to the net. Maternal education was associated with greater use of insecticide-treated bed nets (Oyedeji 2009). The researchers thus concluded that there was a need to enlighten the public concerning the use of ITNs (Oyedeji, 2009). This called for the lowered price of the IRS for affordability and ease of accessibility. When comparing ITNs with IRS, the rate of using ITNs for under five years old is quite prevalent than the rate of using the IRS. 


\section{MATERIAL AND METHODS}

This study is a quantitative study because of the closed-ended nature of questions. It was carried out on assessing the effectiveness of IRS in the prevention of malaria among under five years age children in Ikorodu area of Lagos State, Nigeria. Structured interviews and questionnaire were used to address the objectives of the study. Primary data were collected through an interview in household areas.

The survey was conducted for 10 days through a personal interview from 15th January 2020 to 24th January, 2020. Since the researcher is uncertain about the exact number caregivers in the study area, judgment was made about the confidence level and the error allowance. The error allowance was 0.05 based on the discretion of the researcher. The formulae for achieving sample size $n=z 2 / 4 E 2$ adopted from Zikmund (2003)

Where;

$\mathrm{n}=$ Sample size;

$\mathrm{Z}=\mathrm{Z}$ score for the confidence interval 1.96;

$\mathrm{E}=$ Error allowance 0.05 .

The sample size was approximated to four hundred (400) respondents; hence, 400 questionnaires were distributed to respondents in the study area. From the questionnaire distributed, 215 questionnaires were retrieved from eligible caregivers of under-five children and pregnant women in the households within the selected compounds, and validated for data analysis and reporting.

All the people who were approached consented to participate in the study. A semi-structured interviewer-administered questionnaire was used to collect information on the sociodemographic characteristics of respondents, knowledge of malaria prevention and knowledge of IRS usage, and perception of IRS use in malaria prevention. Knowledge about malaria prevention and IRS use was assessed through a six-point score.

The mean knowledge score was used to dichotomize knowledge scores. Knowledge about malaria prevention was categorized into "good" (4-6) and "poor" (0-3) while scores of 0-4 were deemed poor and 5-6 were considered good for knowledge of IRS use for malaria prevention. Associations between variables were tested using Chi-square with the statistical significance of $5 \%$ (Critical Region). Chi-square was adopted because the sampling technique is non-probability in nature, and the fact that the data types are ordinal and nominal measurement.

\section{RESULTS}

The questionnaire consists of closed-ended questions which address the current status of IRS in Ikorodu Local Government Area. The questionnaires were administered to 400 respondents but only 215 questionnaires were carefully and fully completed and hence, were considered useful for this analysis.

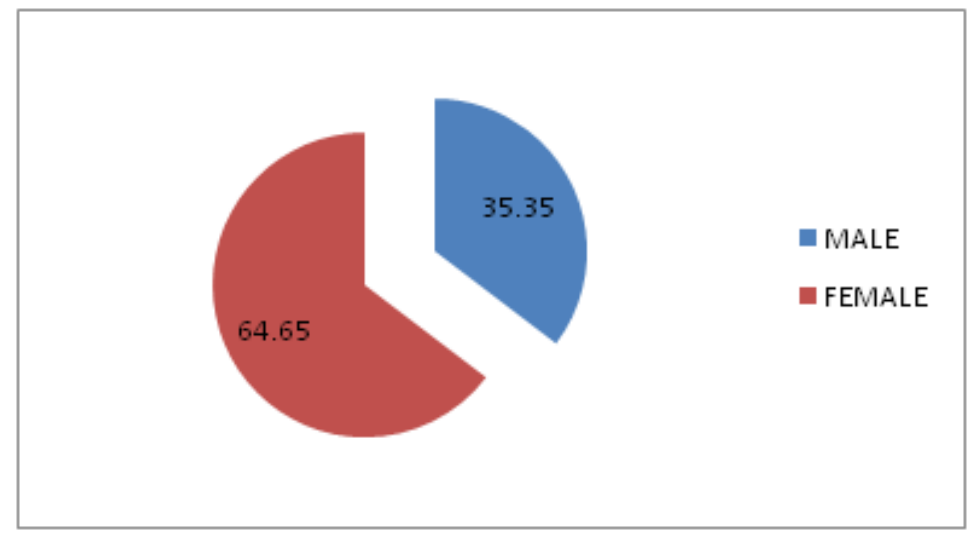

Figure4.1. Socio-demographic characteristics (Gender) of respondents

Source: Authors' Survey

From figure 4.1 above, the socio-demographic characteristics of respondents revealed that about 64.65 per cent of respondents are females while 35.35 per cent are males. This shows that the management of homes is mostly done by females. Hence, there is gender sensitivity. The mean age of female respondents is 39 years and that of male respondents is 44 years. 
Assessing the Effectiveness of Indoor Residual Spraying (IRS) in the Prevention of Malaria among Children of Under Five Years Old In Ikorodu Local Government, Lagos State, Nigeria

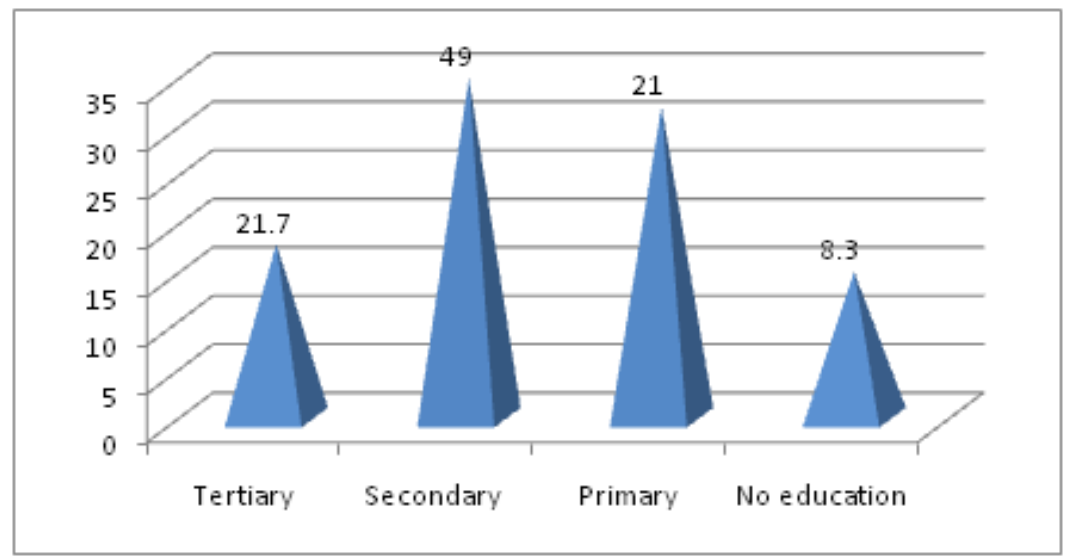

Figure4.2. Socio-demographic characteristics (Education level) of respondents

Source: Authors' Survey

The above figure depicts the education level of respondents. 8.3 per cent of the population had no formal education, 21 per cent of respondents completed their primary education, 49 per cent had at least completed secondary education, and 21.7 per cent had post-secondary or tertiary education. The information gathered from the above can be interpreted that there is a high level of literacy among the respondents in Ikorodu Local Government Area of Lagos state. This is a pointer to the fact that the respondents will be knowledgeable about IRS and its application.

Table 4.1. Respondents Attitude towards IRS and Its Usage

\begin{tabular}{|c|c|c|c|}
\hline Attributes & Agree $(\%)$ & Don’t know (\%) & Disagree $(\%)$ \\
\hline $\begin{array}{l}\text { It is very effective more than other types of } \\
\text { preventive }\end{array}$ & 63.4 & 15.4 & 21.2 \\
\hline $\begin{array}{l}\text { It does not make any difference in malaria } \\
\text { prevention }\end{array}$ & 16.3 & 22.8 & 60.9 \\
\hline IRS smells badly & 6.8 & 21.7 & 71.5 \\
\hline IRS causes irritation & 3.2 & 22.5 & 74.3 \\
\hline IRS causes heat rashes & 3.3 & 22.8 & 73.9 \\
\hline IRS causes cough/illness & 1.6 & 24.7 & 73.7 \\
\hline IRS causes nightmares/bad dreams & 0.8 & 26.5 & 72.7 \\
\hline $\begin{array}{l}\text { The chemical in IRS can kill under five years old } \\
\text { children }\end{array}$ & 0.5 & 28.2 & 71.4 \\
\hline The use of IRS can cause miscarriage & 0.3 & 27.3 & 72.4 \\
\hline $\begin{array}{l}\text { The use of IRS can cause vomiting for under five } \\
\text { years old children }\end{array}$ & 1.6 & 24.9 & 73.5 \\
\hline IRS cannot kill mosquitoes & 4.1 & 42.3 & 53.6 \\
\hline IRS is not readily available & 21.7 & 16.6 & 61.6 \\
\hline IRS is expensive & 24.9 & 8.7 & 66.4 \\
\hline Window nets/door nets are better than IRS & 5.5 & 60.9 & 33.6 \\
\hline $\begin{array}{l}\text { Either you use IRS or not the children that will } \\
\text { have malaria will still have it }\end{array}$ & 19.2 & 24.7 & 56.1 \\
\hline
\end{tabular}

Source: Author's Survey

From the above table, $63 \%$ agrees that the IRS is very effective more than other types of malaria preventives while $21.2 \%$ disagrees. It is obvious that IRS has been tested and seems effective by the people residing in Ikorodu Local Government Area of Lagos state. 71.4\% disagrees that the chemical in IRS can kill under five years old children while $0.5 \%$ agrees. Also, $56.1 \%$ disagrees that either you use IRS or not the children that will have malaria will still have malaria while 19.2 agrees. The reality of the first statement can be seen in the second statement and the reality of the second statement can be seen in the third statement. Hence, the reality of the first statement can be seen in the second and third statements.

To test the null hypothesis which states that there is no association between the education level of respondents and their knowledge of IRS. Chi-square test will be used. 
Assessing the Effectiveness of Indoor Residual Spraying (IRS) in the Prevention of Malaria among Children of Under Five Years Old In Ikorodu Local Government, Lagos State, Nigeria

Table 4.2. Contingency Table Showing the Relationship between Education Level and Knowledge of Respondents towards IRS and its Usage.

\begin{tabular}{|l|c|c|c|c|}
\hline Education & $\begin{array}{c}\text { High (knowledge) } \\
(\%)\end{array}$ & $\begin{array}{c}\text { Medium } \\
\text { (knowledge) }(\%)\end{array}$ & $\begin{array}{c}\text { Low or no } \\
(\text { knowledge) }(\%)\end{array}$ & TOTAL (\%) \\
\hline Highly & 15 & 1.9 & 1 & $\mathbf{1 7 . 9}$ \\
\hline Middle & 10 & 17 & 8 & $\mathbf{3 5}$ \\
\hline Little Low & 2.1 & 22 & 4 & $\mathbf{1 5}$ \\
\hline No & 4 & 7 & $\mathbf{2 1}$ & $\mathbf{1 0 0}$ \\
\hline TOTAL & $\mathbf{3 1 . 1}$ & $\mathbf{4 7 . 9}$ & & \\
\hline
\end{tabular}

Source: Authors' Survey

$\mathrm{H}_{0}$ : There is no association between the education level of respondents and their knowledge of IRS.

$\mathrm{H}_{1}$ : There is an association between the education level of respondents and their knowledge of IRS.

At 0.05 critical region (significance level), determine the table value when the Degree of Table 4.3. Chi-Square test
Freedom is $(\mathrm{R}-1)(\mathrm{C}-1)$. Where $\mathrm{R}$ is the row and $\mathrm{C}$ is the column.

Degree of freedom $=(4-1)(3-1)=6$

At the 0.05 significance level, the degree of freedom 6 gives a table value of 12.59

To compute the test statistics using Chi-square test; $\Sigma\left[(\mathrm{O}-\mathrm{E})^{2} \div \mathrm{E}\right]$

\begin{tabular}{|c|c|c|c|c|}
\hline Observed $(\mathrm{O})$ & Expected $(\mathrm{E})$ & $\mathrm{O}-\mathrm{E}$ & $(\mathrm{O}-\mathrm{E})^{2}$ & $(\mathrm{O}-\mathrm{E})^{2} \div \mathrm{E}$ \\
\hline 15 & 5.57 & 9.43 & 88.93 & 15.97 \\
\hline 1.9 & 8.57 & -6.67 & 44.49 & 5.19 \\
\hline 1 & 3.76 & -2.76 & 7.62 & 2.03 \\
\hline 10 & 10.89 & -0.89 & 0.79 & 0.07 \\
\hline 17 & 16.77 & 0.23 & 0.05 & 0.00 \\
\hline 8 & 7.35 & 0.65 & 0.42 & 0.06 \\
\hline 2.1 & 9.98 & -7.88 & 62.09 & 6.22 \\
\hline 2.2 & 15.38 & 6.62 & 43.82 & 2.85 \\
\hline 8 & 6.74 & 1.26 & 1.59 & 0.24 \\
\hline 4 & 4.67 & -0.67 & 0.45 & 0.10 \\
\hline 7 & 7.19 & -0.19 & 0.04 & 0.01 \\
\hline 4 & 3.15 & 0.85 & 0.72 & 0.23 \\
\hline
\end{tabular}

Source: Authors' Survey

Hence, the Chi-square test is 32.97.

Table 4.3. as shown above will be further analysed in the figure below to determine the good of fitness:

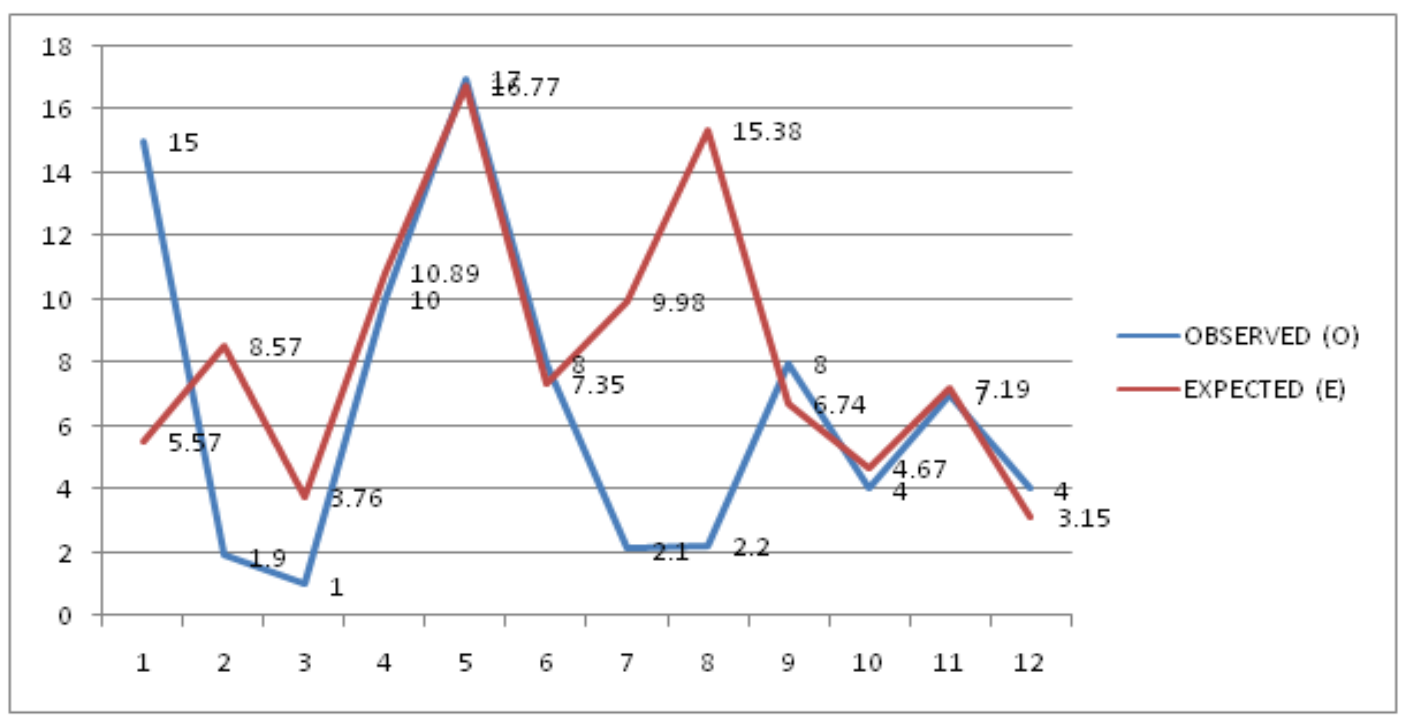

Figure4.3. Chi-square good of fitness

Source: Author's Survey 
It can be noted that the computed value is 32.97 is greater than table value 12.59; hence, we reject the null hypothesis which states that there is no association between the education level of respondents and their knowledge of IRS. This then gives a basis to accept the alternate or research hypothesis which states that there is an association between the education level of the respondent and their knowledge of IRS in Ikorodu Local Government, Lagos State, Nigeria. When comparing the observed and the expected lines in the figure, we can deduce that the fitness or goodness between the two lines is fair. This can be attributed to the nature of the sample.

The study found that there is a high level of literacy among the respondents in Ikorodu Local Government Area of Lagos state, which is a pointer to the fact that the respondents will be knowledgeable about IRS and its application and be positive about the prevention of malaria. IRS is very effective more than other types of malaria preventives, and the chemical in IRS cannot kill under five years old children as perceived by respondents in the study area. This study found that there is an association between the education level of the respondent and their knowledge of IRS in Ikorodu Local Government, Lagos State, Nigeria. As a result of this, it can be observed that the usage of IRS is effective on under five years age children, and the citizens are educated about the usage of IRS. This does not agree with the findings of Oyedeji et al. (2009); Lauretta (2014) which emphasized that malaria preventive health behaviours in Nigeria are poor.

\section{CONCLUSION AND RECOMMENDATIONS}

This study was carried out to assess the effectiveness of IRS in the prevention of malaria among under five years age children in Ikorodu area of Lagos State, Nigeria. The questionnaire consists of closed-ended questions which address the current status of IRS in Ikorodu Local Government Area. The questionnaires were administered to 400 respondents based on purposive sampling technique, but only 215 questionnaires were carefully and fully completed for data analysis. Chi-square was employed for data analysis.

From the information, there is a high level of literacy among the respondents in Ikorodu Local Government Area of Lagos state. This is a pointer to the fact that the respondents will be knowledgeable about IRS and its application.
IRS is very effective more than other types of malaria preventives, and the chemical in IRS cannot kill under five years old children as perceived by respondents in the study area. This study found that there is an association between the education level of the respondent and their knowledge of IRS in Ikorodu Local Government, Lagos State, Nigeria. As a result of this, it can be observed that the usage of IRS is effective on under five years age children, and the citizens are educated about the usage of IRS. Despite the fact that the respondents are knowledgeable about IRS usage and that IRS is effective, there is a need for continous education programmes, engineering solutions, and some form of enforcements so that the effectiveness will be a sweeping transformation.

\section{REFERENCES}

[1] Alilio, M et al. (2004). Are Multilateral Malaria Research and Control Programs the Most Successful? Lessons from the Past 100 Years in Africa. American Journal of Tropical Medicine and Hygiene, 2004, 71 (Suppl 2): 268-278.

[2] Adegun JA, Adegboyega JA, Awosusi A O. (2011). Knowledge and the preventive strategies of Malaria among Migrant Farmers in Ado-Ekiti Local Government Area of Ekiti State, Nigeria. American Journal of Scientific and Industrial Research 2:883-889 DOI 10.5251/ajsir.2011.2.6.883.889.

[3] Adebayo, B. (2015), Knowledge of malaria prevention among pregnant women and female caregivers of under-five children in rural southwest Nigeria. PeerJ 3:e792; DOI 10.7717/peerj.792.

[4] Adeniran, A. O., and Oyemade, H. (2016). Inventory Analysis of Solid Waste Management in Ikorodu Community. Journal of Civil and Environmental Research, 8(9), 2638 .

[5] Adongo PB, Kirkwood B, Kendall C. (2005). How local community knowledge about malaria affects insecticide-treated net use in northern Ghana. Tropical Medicine \& International Health 10:366-378 DOI 10.1111/j.1365-3156.2005.01361.

[6] Ahorlu CK, Dunyo SK, Afari EA, Koram KA, Nkrumah FK. 1997. Malaria-related beliefs and behaviour in Southern Ghana: implications for treatment, prevention and control. Tropical Medicine \& International Health 2:488-499 DOI 10.1111/j.1365-3156.1997.tb00172.

[7] Alcalay, R., \&Bell, R. (2000). "Social Marking its definition and domain" Journal of public policy and marketing, 13 (1), 108-114.

[8] Barreto A (1996) Malaria in Mozambique what had been done to control epidemics. 
Assessing the Effectiveness of Indoor Residual Spraying (IRS) in the Prevention of Malaria among Children of Under Five Years Old In Ikorodu Local Government, Lagos State, Nigeria

Department of Epidemiology, Ministry of Health, Maputo, Mozambique (unpublished).

[9] Breman J., Alilo, M., Mills, A., (2004). "Conquering the intolerable burden of malaria, what's new, what's needed: a summary. Journal of tropical medicine and hygiene, vol. 1, pp. 15. available at: google.com/pdf.

[10] Fakeye TO, Adisa R, Musa I. E. (2009). Attitude and use of herbal medicines among pregnant women in Nigeria. BMC Complementary and Alternative Medicine 9:53 DOI 10.1186/1472 6882-9-53.

[11] Falade CO, Ogundiran MO, Bolaji MO, Ajayi IO, Akinboye DO, Oladepo O, Adeniyi JD, Oduola A. M. (2006). The influence of cultural perception of causation, complications, and severity of childhood malaria on determinants of treatment and preventive pathways. International Quarterly of Community Health Education 24:347-363 DOI 10.2190/GN669447-3984-4064.

[12] Fawole AO, Onyeaso N. C. (2008). Perception and practice of malaria prophylaxis in pregnancy among primary health care providers in Ibadan, Nigeria. West African Journal of Medicine 27:92-96.

[13] Federal Ministry of Health Abuja. (2005). National malaria control programme annual report.

[14] Abuja: Federal Ministry of Health, Nigeria.

[15] Federal Ministry of Health (2001). A technical report on the 2000 National malaria control Survey among pregnant women attending antenatal clinics, National malaria control programme.

[16] Federal Ministry of Health (2001) Index on Malaria Control in Nigeria.

[17] Federal Ministry of Health (2003). Malaria Control in Nigeria.

[18] Federal Ministry of Health (2004). Malaria Control in Nigeria: A strategy for Behaviour Change Communication, 2004-2005.

[19] Federal Ministry of Health (2005). A 5 years strategic plan: 2006-2010, A Road map for Impact of Malaria in Nigeria.

[20] Federal Ministry of Health (2011). National Guidelines for Diagnosis and Treatment of Malaria, National Malaria and Vector Control Division.

[21] Hanson et al. (2004). The Economics of Malaria Control Interventions. Geneva, World Health Organization, 2004.

[22] Jacobson, T., and Chang, L. S (2005). "Measuring Community Change as Social Choice".Paper presented at the annual meeting of the International Communication Association, Sheraton New York, New York City. Retrieved on June 10, 2013, from www.allacadmeic.com/meta/p14963.
[23] Jones, .C. (2002). Bed nets and malaria. Postgraduate Doctor Afr. 24, 23-25.

[24] Korenromp E., Miller, J., Gibulski, R. I Kabir Cham M., Alnwick D. \& Dye, C. (2003). "Monitoring mosquito net coverage for malaria controls in Africa: possession vs. use by children under 5 years". International journal of tropical health, vol. 8. pp. 693-703. Retrieved on May 26, 2013, from www.google.com/pdf.

[25] Lamptey, P. Wigley, M. \&Collymore, (2002). "From Corn to Computers: Diffusion of Innovations". Paper Presented at the annual meeting of the NCA 94th Annual Convention, Sam Diego, November 20, 2008. Retrieved March 11, 2013, from www.allafrica. com/ meta/p257398.

[26] Lauretta E. Ovadje (2014). Adherence to the Use of Insecticide-Treated Bed Nets By Nigerian Children. A dissertation submitted in partial fulfilment of the requirements for the degree ofDoctor of Philosophy (Environmental Health Sciences) at the University of Michigan in 2014.

[27] Mabaso1, Musawenkosi L. H., Brian Sharp and Christian Lengeler (2004). Historical review of malarial control in southern African with emphasis on the use of indoor residual housespraying. Tropical Medicine and International Health.volume 9 no 8 pp 846-856 august 2004.

[28] Narasimhan, V., Attaran, A., (2003). "Roll Back Malaria? The Scarcity of International aid for Malaria Control. Accessed on June 6, 2013, from www.rbm.int/and2003/amr_toc.htm

[29] Orimadegun, A. Fawole, O., Okereke, J., Akinbami F., \&Sodeinde, O. (2007). "Increasing burden of childhood severe malaria in a Nigeria tertiary hospital: implications for control". Journal of Tropical Paediatrics, 53:185-9.

[30] Osero, J., Oteino, M., Orago, A. (2005). "Maternal Use of Insecticide Treated Nets in the prevention of malaria among children under five years in Nyamira District, Kenya". Med. Journal, vol. 32, 495-500.

[31] Oyedeji, O. Elemile, P. Adepoju, A \&Oyedeji, G. (2009). "An evaluation of the use of insecticide-treated bed nets among children presenting with malaria at a Nigeria health Facility. International Journal of Medicine and Medical Sciences. Vol. 1 (11) pp. 501-504, November 2009. Available online at http://www.academicjournal.org/ismms.

[32] Rogers, E. (2003). Diffusion of Innovations ( $5^{\text {th }}$ Edition). New York: Free Press.

[33] SAMC. (2000). Malaria methods: towards better-informed malaria control in Southern Africa. Southern African Malaria Control (SAMC)/WHO, Zimbabwe, 2000. 
Assessing the Effectiveness of Indoor Residual Spraying (IRS) in the Prevention of Malaria among Children of Under Five Years Old In Ikorodu Local Government, Lagos State, Nigeria

[34] World Health Organization (2006). Malaria vector control and personal protection: report of a WHO study group. WHO Technical Report Series 936, Geneva, World Health Organization, 2006.

[35] World Health Organization (WHO), Africa (2007). Implementation of Indoor Residual Spraying of Insecticides for Malaria Control in the WHO African Region Report. Vector Biology and Control Unit Division of Healthy Environments and Sustainable Development World Health Organization for Africa, November 2007. Pp. 1-70.
[36] World Health Organization (WHO) (2006). Global Malaria Programme Indoor residual spraying Use of indoor residual spraying for scaling up global malaria control and elimination. WHO/HTM /MAL/2006.1112. Pp. $1-16$.

[37] Yamey, G. (2004). "Roll Back Malaria: A failing global health campaign" BMJ. Vol 328. Pp 1086-1087. Retrieved on May 26, 2013, from www.google.com/PDF.

[38] Zikmund, W. G. (2003). Business research methods $\left(7^{\text {th }}\right.$ ed.). South-Western.

Citation: Oluwadamisi Tayo-Ladega, "Assessing the Effectiveness of Indoor Residual Spraying (IRS) in the Prevention of Malaria among Children of Under Five Years Old In Ikorodu Local Government, Lagos State, Nigeria", International Journal of Research Studies in Medical and Health Sciences. 2020; 5(11): 114.

Copyright: () 2020 Oluwadamisi Tayo-Ladega, This is an open-access article distributed under the terms of the Creative Commons Attribution License, which permits unrestricted use, distribution, and reproduction in any medium, provided the original author and source are credited. 